\title{
Posterior hemivertebra resection with unilateral instrumented fusion in children less than 10 years old: preliminary results at minimum 5-year follow-up
}

Xuhong Xue and Sheng Zhao*

\begin{abstract}
Background: The main treatment for congenital hemivertebra is posterior hemivertebrectomy with bilateral transpedicular fixation. To date, studies describing posterior unilateral fusion are few, especially in younger children. The modified method by posterior hemivertebrectomy combined with unilateral transpedicular instrumentation and fusion was described. The purpose was to present the clinical and radiological outcome of children less than 10 years treated for congenital scoliosis with posterior hemivertebrectomy and unilateral instrumented fusion.

Methods: A study of 43 consecutive patients through Jan. 2006 to Mar. 2013 for hemivertebrae in children less than 10 years was performed. Patients undergoing hemivertebrectomy and posterior convex short-segment fusion, which had been followed up for at least 60 months, were included. Coronal main curve, kyphosis, T1-S1 height, fused vertebra height, and concave height were measured at preoperation, immediate postoperation, and final follow-up. The outcome and efficacy of the correction provided and growth of the non-fused concave side of the spine was investigated.

Results: The average follow-up period was $73.88 \pm 16.77$ months. The mean Cobb angle of the coronal curve was improved from 46.1 to $8.1^{\circ}$ (correction rate $82.4 \%$ ). At final follow-up, there was $7.8 \%$ loss of correction. The average concave height, fusion segment height, and T1-S1 height were $60.1 \pm 19.7 \mathrm{~mm}, 56.9 \pm 22.9 \mathrm{~mm}$, and $326.6 \pm 64.5 \mathrm{~mm}$ in immediate postoperation, which improved to $73.1 \pm 23.7 \mathrm{~mm}, 71.2 \pm 22.0 \mathrm{~mm}$, and $388.7 \pm 78.9 \mathrm{~mm}$ at the last follow-up. These parameters were significantly different between the immediate postoperation and at final follow-up. The rate of reoperation was 9.3\% (4/43), mainly in PJK and curve progression after surgery.

Conclusions: Despite with some complications, posterior hemivertebrectomy and unilateral instrumented fusion are commendable procedures. We concluded that it is a simple, secure, reliable, less-invasive, and well-tolerated technique that can successfully resolve this kind of congenital scoliosis in children.
\end{abstract}

Keywords: Hemivertebrae, Unilateral fusion, Hemivertebrectomy, Congenital scoliosis

\footnotetext{
*Correspondence: zhaosheng0807@163.com

Department of Orthopedics, The Second Hospital of Shanxi Medical

University, Taiyuan, No. 382 Wuyi Road, Taiyuan 030001, Shanxi, People's

Republic of China
}

(C) The Author(s). 2018 Open Access This article is distributed under the terms of the Creative Commons Attribution 4.0 International License (http://creativecommons.org/licenses/by/4.0/), which permits unrestricted use, distribution, and reproduction in any medium, provided you give appropriate credit to the original author(s) and the source, provide a link to the Creative Commons license, and indicate if changes were made. The Creative Commons Public Domain Dedication waiver (http://creativecommons.org/publicdomain/zero/1.0/) applies to the data made available in this article, unless otherwise stated. 


\section{Background}

Congenital scoliosis encompasses a continuous bending of spinal deformities, which result from the localized imbalance in the longitudinal growth of the spine caused by asymmetrical development of one or more vertebras [1]. It may be classified into failures of formation, failures of segmentation, or mixed deformities [2]. The most common anomaly caused by failure of formation is the hemivertebra. Based on pathological features, hemivertebra has been described to three types including (1) the fully segmented, (2) the semi-segmented, and (3) the incarcerated types [3]. Incarcerated hemivertebra and a balanced trunk usually have a benign result, while non-incarcerated hemivertebra has a normal-growth plate leading to progression of a wedge-shaped deformity. Scoliosis caused by non-incarcerated hemivertebra is more rigid than other types, which is difficult to correct by conservative treatment such as back brace and cast, which often requires surgery for correction [4, 5].

Posterior or anterior convex growth arrest (CGA) has been used to the treatment of early-onset congenital scoliosis [6]. Although successful results have been reported with the technique, the failure rates ranging from 8 to $21 \%$ have also been reported [7]. Several drawbacks of the classic CGA have also been described. On the one hand, the need for an additional anterior procedure has been one of the most worrisome drawbacks of the procedure. On the other hand, some problems such as being unable to obtain acute correction and unpredictability of gradual correction after surgery have been reasons of failure in CGA [8].

To negate the previously mentioned drawbacks, the technique has been modified. We applied pedicle screws through the posterior approach on the convex short-segment instrumentation aiming to control convex growth. Meanwhile, hemivertebra resection via the posterior approach was adopted aiming to achieve acute correction. Personalized hemivertebra excision was introduced to balance the growth potential in both sides of the spine. It can achieve convex growth arrest and preserve concave growth potential at the same time. The outcome and efficacy of this technique has been investigated in the present study.

\section{Methods}

With the approval of the institution's Institutional Review Board, 43 consecutive patients with hemivertebrae younger than 10 years of age were treated using hemivertebrectomy and posterior convex short-segment fusion through Jan. 2006 to Mar. 2013 at a single spine center. They had been followed up for at least 60 months. There were 23 boys and 20 girls. There were 22 fully segmented and 21 semi-segmented hemivertebra. The hemivertebra was located within the thoracic spine (T1-
T11) in 27 cases, within the thoracolumbar region (T12-L1) in seven cases, and within the lumbar spine (L2-L5) in 11 cases. Three patients had contralateral bar formation and synostosis of the ribs. Most of abnormal vertebra was located at the right side, only three cases within the left side. We used a $4.5-\mathrm{mm}$ rod with polyaxial pediatric posterior instrumentation screws of $4.0-\mathrm{mm}$ diameter in six patients whose ages were below 3 years, and we used a $5.5-\mathrm{mm}$ rod with a 4.75 - or $5.0-\mathrm{mm}$-diameter pediatric posterior instrumentation screws in the remaining 37 patients (Bonovo Orthopedics, Inc).

Preoperative evaluation included a thorough neuromuscular examination, routine radiographs, 3-dimensional computed tomography scan, and magnetic resonance imaging due to increased incidence of intraspinal abnormalities associated with congenital scoliosis. Cardiovascular and urogenital examinations were performed to detect congenital heart diseases and abnormalities of the renal system. None of the patients had undergone a prior operation. None had a neurologic deficit or cord anomaly. Surgery was indicated by proved or expected deterioration of the deformity.

Preoperation, immediate postoperation, and final follow-up standing posteroanterior and lateral radiograms were evaluated. Coronal main curve was recorded for the instrumented segment. Global thoracic kyphosis was measured between T2 and T12 on a sagittal plane. These values were compared preoperatively, postoperatively, and at last follow-up. The height between $\mathrm{T} 1$ and S1 was determined by the vertical distance from the midpoint of the superior endplate of $\mathrm{T} 1$ to the midpoint of the superior endplate of S1 (Fig. 1a). The height of fusion segment was determined by the vertical distance from the midpoint of the superior endplate of the upper instrumented vertebra (UIV) to the midpoint of the superior endplate of the lowest instrumented vertebra (LIV) (Fig. 1b). The height between the concave side pedicles of the upper- and lower-end vertebra of the main curve was also determined and recorded as the concave height (Fig. 1b). These measurements of the height on the radiograph are done digitally in early postoperative and at final follow-up X-rays. Operative reports were reviewed to determine the presence of any intraoperative complication. Medical records were reviewed to identify any complication in the perioperative and follow-up periods. Measurements were taken from standing long-cassette anterior-posterior and lateral radiographs.

\section{Surgical technique}

The patients were positioned prone on the operating table. A standard midline skin incision was used, and subperiosteal dissection was performed on the convex side only to expose the hemivertebra and the vertebrae 


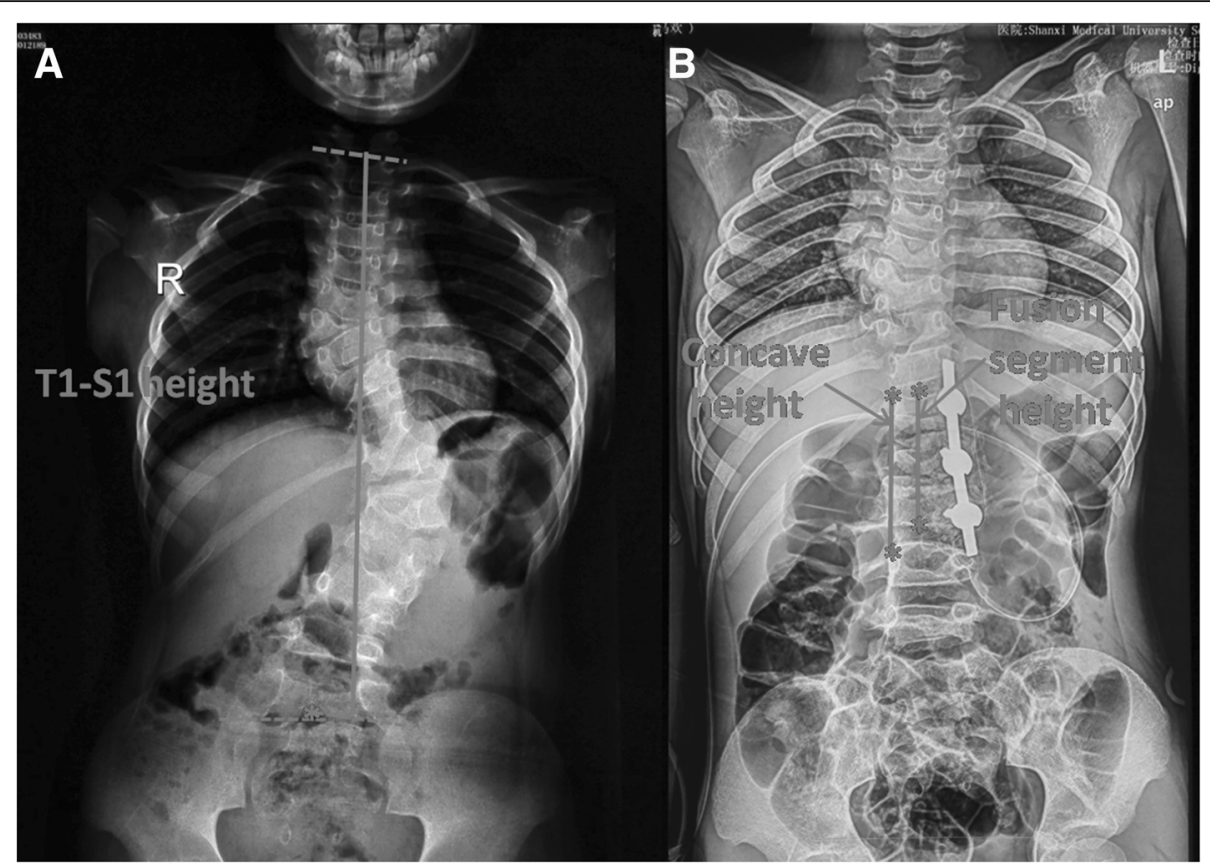

Fig. 1 T1-S1 height: the vertical distance from the midpoint of the superior endplate of T1 to the midpoint of the superior endplate of S1 (a); fusion segment height: vertical distance from the midpoint of the superior endplate of upper UIV to the midpoint of the superior endplate of LIV; concave height: the height between the concave side pedicles of the upper and lower end vertebra of the main curve (b)

just above and below, including the lamina, transverse processes, and facet joints. Fluoroscopy was used for the determination of instrumentation levels. Unilateral pedicle screws were inserted into the vertebra above and the vertebra below using the funnel technique described by Viau et al. [9]. Briefly speaking, the posterior cortex of the lamina overlying the top of the pedicle is removed by a rongeur to make a $6-8$-mm-diameter opening in the cortex. The cancellous isthmus of the pedicle is directly visualized by removing the cancellous bone from the upper part of the pedicle with a small curette. After further removal of the cancellous bone, enlargement of the pedicle funnel leads the curette into the upper part of the pedicle isthmus. The cortical margins of the upper part of the pedicle then act as a funnel to permit safe insertion of the pedicle probe through the pedicle isthmus. Firstly, careful probing of the pedicle is then performed with the 2-mm probe, and then, if the pedicle inner diameter allows it, with the larger pedicle probe. At last, a ball-tip probe is used to inspect the depth of the opening as well as all four walls of the pedicle for a perforation (Fig. 2a).

The posterior parts of the pedicle were removed; inferior half of the lamina above was excised including the inferior articular process, and then, the superior articular process of the hemivertebra was excised (Fig. 2b). This was followed by excision of the inferior articular process of the hemivertebra and the superior articular process of the vertebra below. If in the thoracic spine, the rib head was also removed. The spinal cord and the nerve roots were identified and protected, as well as the pleura. Epidural veins were cauterized by bipolar cautery to allow clear visualization. The remnants of the vertebral body of the hemivertebra and the adjacent disks were removed. The vertebral end plates of the convex side were debrided down to the bone, and the contralateral end plate was retained (Fig. 2c). The concave side was not exposed as continued spinal growth on this side will improve the correction in 40 patients. Subsequently, a pre-contoured rod was connected to the screws on the convex side. Gradual compression was applied until the gap was closed. Bones retrieved during osteotomy were used as graft material for fusion of the posterior elements. In cases with contralateral bar formation and multiple rib anomalies, unilateral exposure is not sufficient and bilateral exposure is necessary to cut off the bar or synostosed rib heads. Three cases involved a double hemivertebra or concave bar and multiple rib anomalies, which required extension of the fusion to more segments (Fig. 3). In one patient aged 2.8 years, no appropriately sized pedicle screw was available; therefore, 3.0-mm, cortical screws combined with wires were used as an alternative (Fig. 4). For lumbar or lumbosacral hemiveterbra, unilateral short-segment instrumentation combined with hemivertebra resection was also very applicable.

After surgery, all patients were fitted with a rigid brace to protect the instrumentation for at least 6 months. 


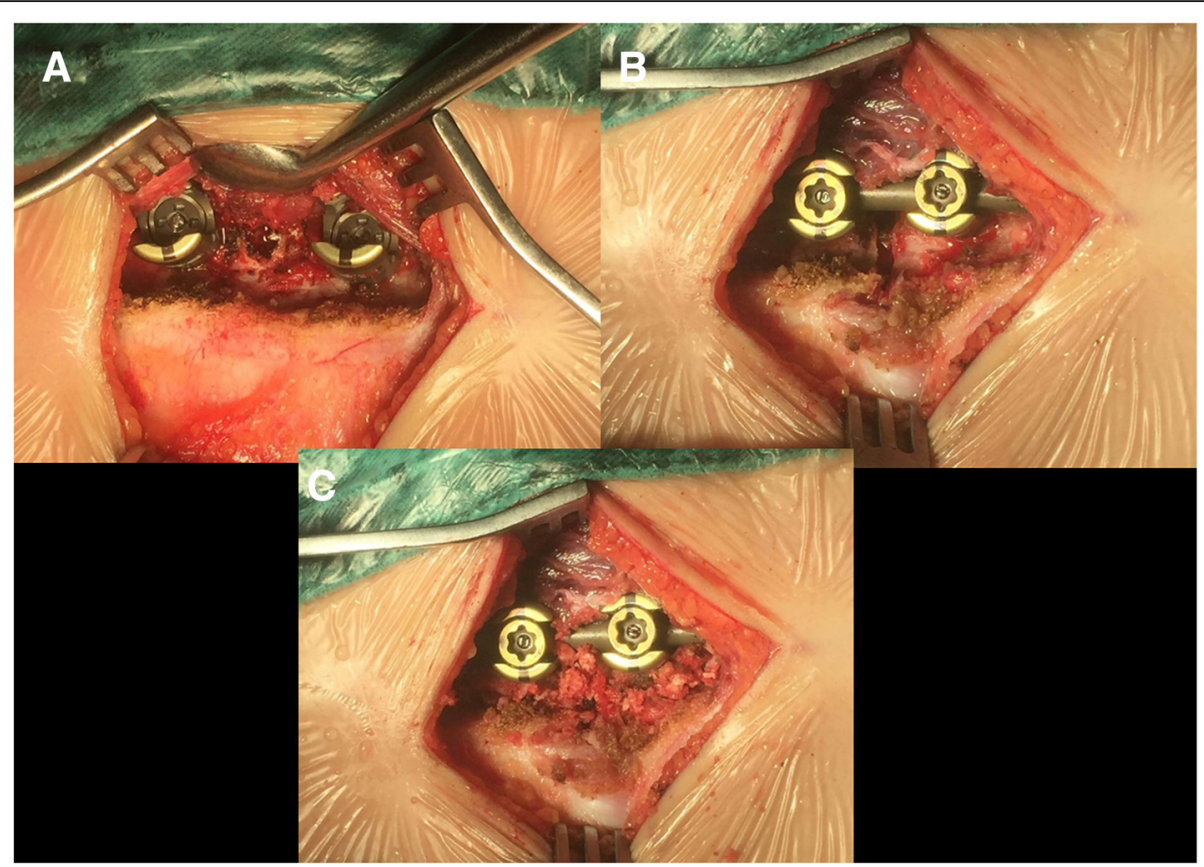

Fig. 2 Interoperation image: convex side only to expose the hemivertebra, and unilateral pedicle screws were inserted into the vertebra using the funnel technique (a). Hemivertebra resection: the vertebral end plates of the convex side were excised (b). Gradual compression until the gap was closed. Bone graft for fusion of the posterior elements (c)

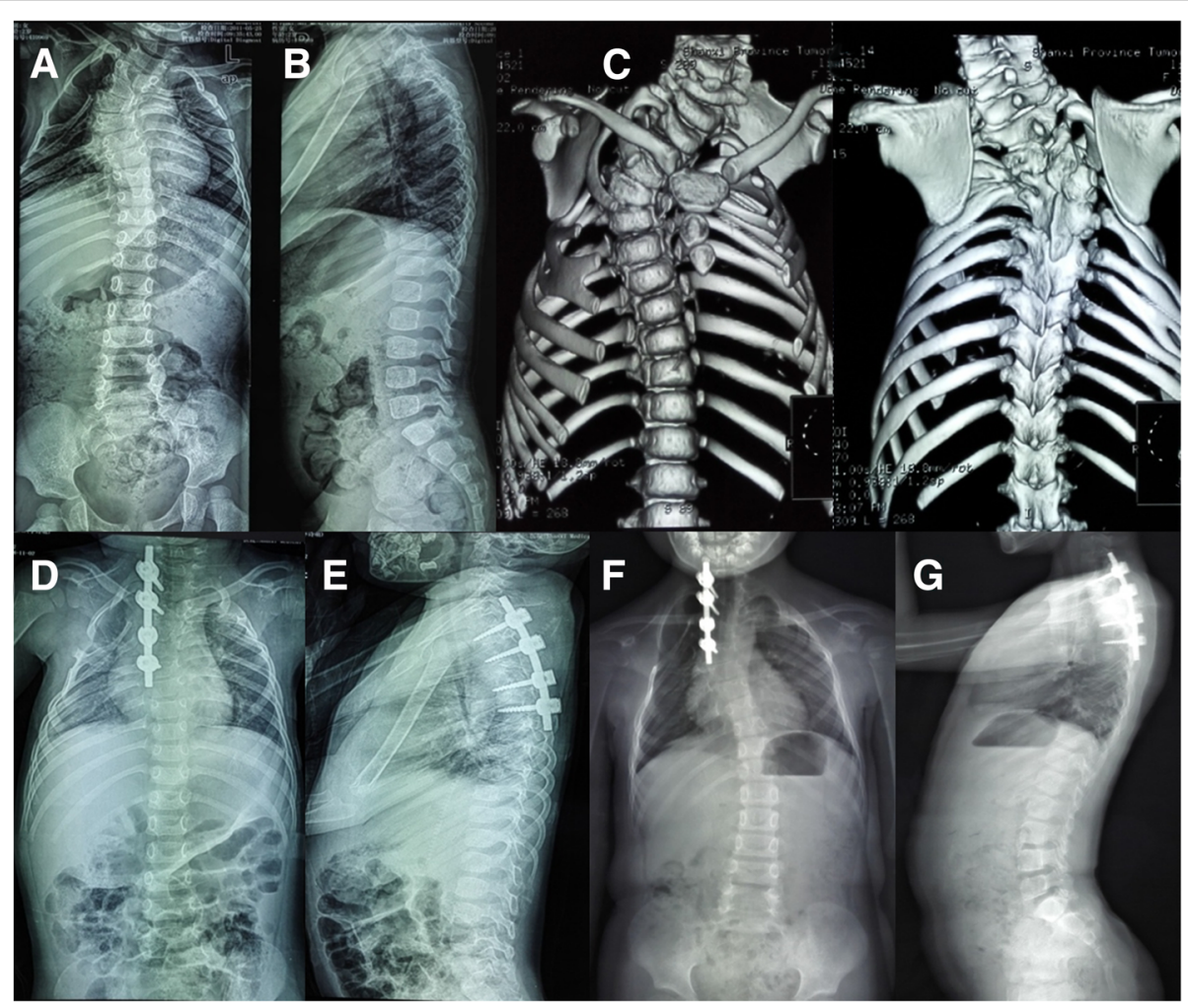

Fig. 3 A 2 years and 4 months old girl with congenital scoliosis. Radiographs and 3D-computed tomography images obtained preoperatively $(\mathbf{a}, \mathbf{b}, \mathbf{c})$, postoperatively $(\mathbf{d}, \mathbf{e})$, and at the latest follow-up visit, 60 months later $(\mathbf{f}, \mathbf{g})$ 


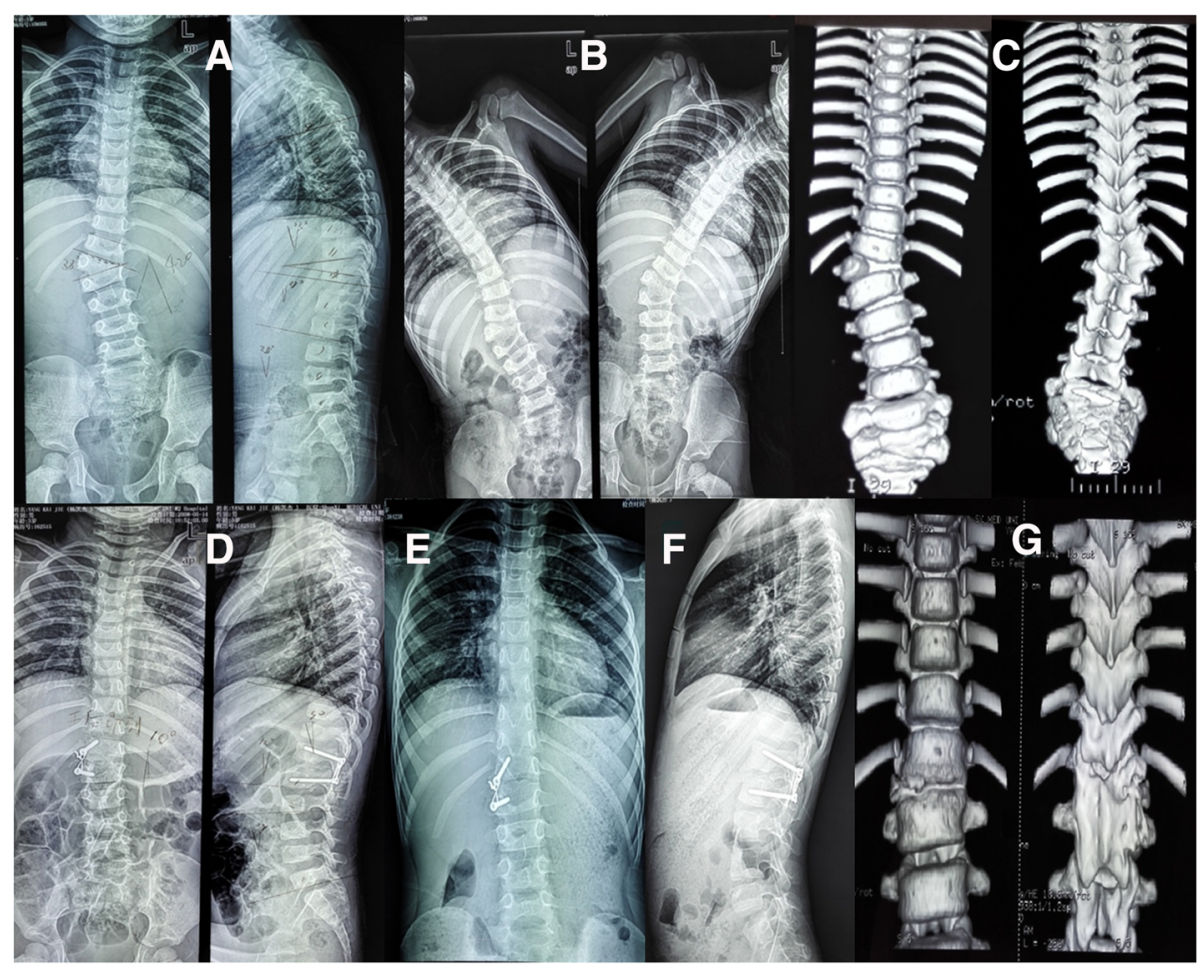

Fig. 4 A 2 years 9 months old girl with T12 hemivertebra. Radiograph images and 3D-computed tomography images obtained preoperatively $(\mathbf{a}-\mathbf{c})$, postoperatively $(\mathbf{d})$, and at the latest follow-up visit, 69 months later $(\mathbf{e}, \mathbf{f}, \mathbf{g})$

\section{Statistics}

Paired $t$ test was used to analyze the difference of coronal curve angle, thoracic kyphosis, segmental kyphosis, T1-S1 height, fusion segment height, and concave height at preoperation, postoperation, and final follow-up. SPSS version 17.0 (SPSS Inc., Chicago, IL) was used in all statistical analyses. The differences with a $P$ value less than 0.05 were considered as statistically significant.

\section{Results}

Of the 43 patients, 10 had rib anomalies, 3 had concave unsegmented bar, 1 had congenital cardiac anomalies, and 6 had intraspinal anomalies. No intraoperative complications were noticed. There were no neurologic complications. No implant failure was found at the final radiographic evaluations. Four patients experienced reoperation, and the overall rate of reoperation was 9.3\%; demographic data are summarized in Table 1. The reasons of reoperation included two proximal junctional kyphosis (Fig. 5) and two curve progressions in the distal junction. In total, the average follow-up period was $73.88 \pm 16.77$ months (range, 60 to 112 months). Average age of the patients at surgery was 6 years and 7 months (range, 2 to 10 years).

Table 1 Patients' demographic data in revision surgery

\begin{tabular}{|c|c|c|c|c|c|c|c|c|c|}
\hline Patients & Sex & Age & Abnormality & $\begin{array}{l}\text { Association } \\
\text { anomalies }\end{array}$ & Revision reason & Initial surgery & $\begin{array}{l}\text { Duration } \\
\text { time (months) }\end{array}$ & Revision surgery & $\begin{array}{l}\text { Final F/U } \\
\text { (months) }\end{array}$ \\
\hline 1 & M & 8 & $\begin{array}{l}\text { HV:T5; } \\
\text { Unsegment } \\
\text { T3-7 }\end{array}$ & $\begin{array}{l}\text { Sprengel } \\
\text { deformity }\end{array}$ & PJK & $\begin{array}{l}\text { T5 HV resection with } \\
\text { T4-7 convex fusion }\end{array}$ & 11 & $\begin{array}{l}\text { T2 PSO with T1-3 } \\
\text { convex fusion }\end{array}$ & 112 \\
\hline 2 & M & 2 & $\mathrm{HV}: \mathrm{T} 12$ & - & $\begin{array}{l}\text { PJK due to T11 } \\
\text { pedicle fracture }\end{array}$ & $\begin{array}{l}\text { T12 HV resection with } \\
\text { T10-L2 convex fusion }\end{array}$ & 12 & $\begin{array}{l}\text { T11 Y-shape osteotomy } \\
\text { with T9-L2 convex fusion }\end{array}$ & 45 \\
\hline 3 & $\mathrm{~F}$ & 7 & $\begin{array}{l}\text { HV:T6; } \\
\text { Unsegment } \\
\text { T5-9 }\end{array}$ & $\begin{array}{l}\text { Fused rib in } \\
\text { concave }(9-10)\end{array}$ & $\begin{array}{l}\text { Curve progression } \\
\text { in distal junction }\end{array}$ & $\begin{array}{l}\text { T6 HV resection with } \\
\text { T5-7 convex fusion }\end{array}$ & 27 & $\begin{array}{l}\text { T7 PSO with T5-10 } \\
\text { convex fusion }\end{array}$ & 80 \\
\hline 4 & M & 5 & $\begin{array}{l}\text { HV:T6; BF:T10; } \\
\text { Unsegment } \\
\text { L2-3 }\end{array}$ & - & Curve progression & $\begin{array}{l}\text { T6 HV resection with } \\
\text { T3-9 convex fusion }\end{array}$ & 78 & $\begin{array}{l}\text { Bilateral fusion from } \\
T 3 \text { to } L 3\end{array}$ & 90 \\
\hline
\end{tabular}




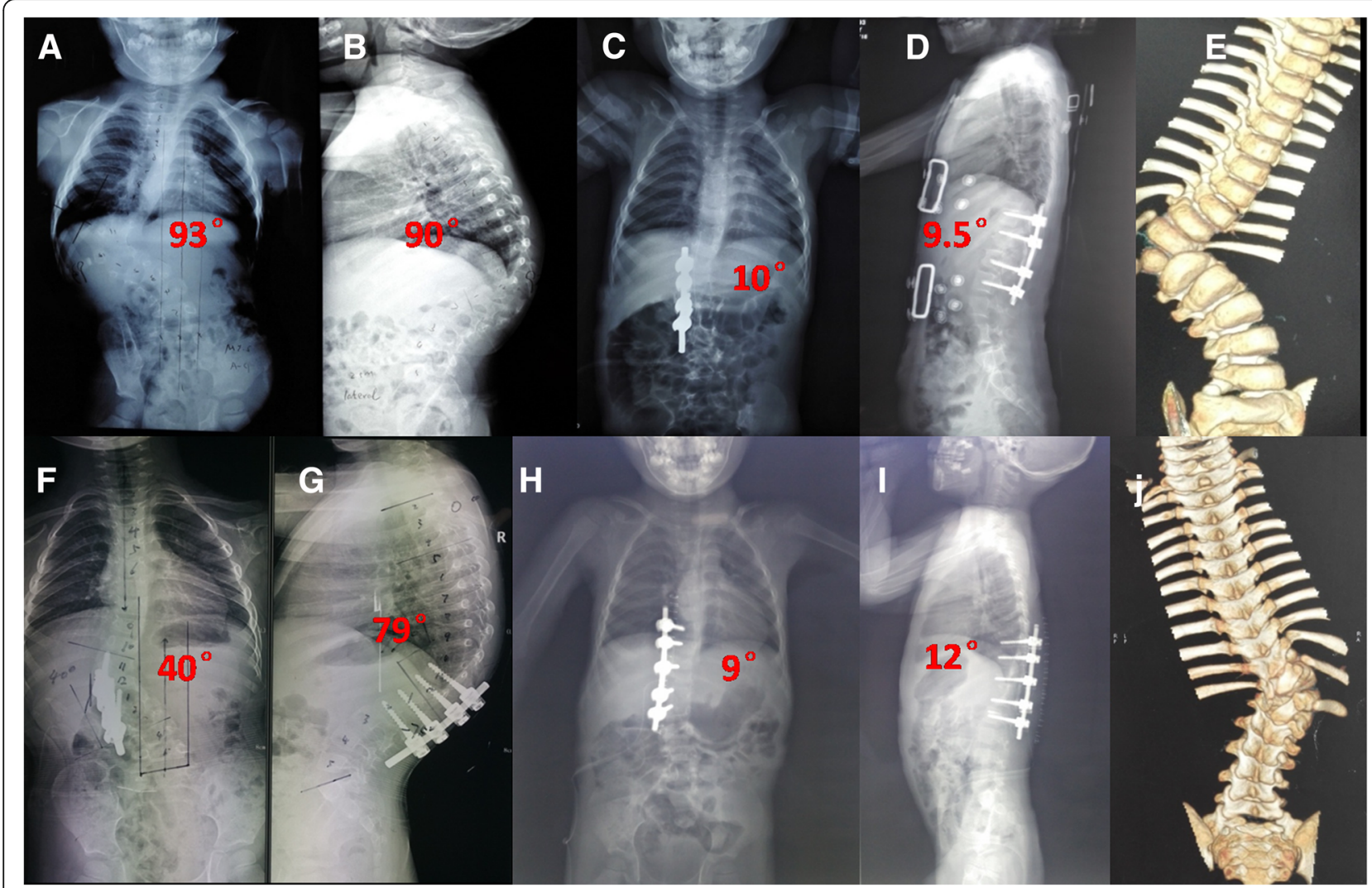

Fig. 5 A 2.5-year-old boy with T12 hemivertebra. Radiograph images and 3D-computed tomography images obtained preoperatively (a, b, e, j), postoperatively $(\mathbf{c}, \mathbf{d})$, and at the latest follow-up visit, 12 months later $(\mathbf{f}, \mathbf{g})$ and revision surgery $(\mathbf{h}, \mathbf{i})$

There were no major vascular or neurological complications.

When all the patients were evaluated together, the average coronal curve magnitude was $46.1 \pm 19.6^{\circ}$ (range, 21 to $93^{\circ}$ ) preoperatively, $8.1 \pm 9.6^{\circ}$ (range, 0 to $37^{\circ}$ ) immediate postoperatively, and $11.7 \pm 12.2^{\circ}$ ( 3 to $49^{\circ}$ ) at last follow-up. The difference between the preoperative and early postoperative main curve Cobb angle measurements was significant $(P=0.000)$. At the latest follow-up, there was $7.8 \%\left(3.6^{\circ}\right)$ loss of correction. The global thoracic kyphosis was $35.5 \pm 21.7^{\circ}$ (range, 18 to $72^{\circ}$ ) preoperatively, $34.9 \pm 7.7^{\circ} \quad\left(15\right.$ to $\left.41.5^{\circ}\right)$ immediate postoperatively, and $37.6 \pm 7.5^{\circ}$ (19 to $\left.44^{\circ}\right)$ at last follow-up. The segmental kyphosis was $23.3 \pm 27.2^{\circ}$ (3 to $90^{\circ}$ ) preoperatively, $10.1 \pm 3.1^{\circ}$ ( 9 to $15^{\circ}$ ) immediate postoperatively, and $7.4 \pm 7.2^{\circ}\left(1\right.$ to $22^{\circ}$ ) at the last follow-up assessment resulting in a mean improvement of $13.2^{\circ}$ postoperatively, and this improvement continued at the latest follow-up with a mean increase of $2.7^{\circ}$ (Table 2 ).

The average concave height was $60.1 \pm 19.7 \mathrm{~mm}$ in the immediate postoperative period and $73.1 \pm 23.7 \mathrm{~mm}$ at last follow-up. There was a significant difference between immediate postoperative and at last follow-up measurements $(P=0.003)$. The average fusion segment height was $56.9 \pm 22.9 \mathrm{~mm}$ in the immediate postoperative period and $71.2 \pm 22.0 \mathrm{~mm}$ at last follow-up $(P=$ $0.002)$. The average T1-S1 height was $326.6 \pm 64.5 \mathrm{~mm}$ in the immediate postoperative period and $388.7 \pm$ $78.9 \mathrm{~mm}$ at last follow-up $(P=0.001)$ (Table 3$)$. The average fusion segment was $2.9 \pm 1.8$ levels (2-6 levels).

\section{Discussion}

The natural history of congenital scoliosis is still unknown. There is no treatment algorithm because of the variability of surgical solutions. The coronal and sagittal deformities, as well as the patient age and type and location of the anomaly, should be taken into consideration. As the most frequent cause of congenital scoliosis, most untreated fully segmented and semi-segmented non-

Table 2 Summary of radiographic parameters preoperatively and postoperatively

\begin{tabular}{llll}
\hline & Preoperation & Postoperation & $P$ value \\
\hline Coronal curve cobb $\left({ }^{\circ}\right)$ & $46.1 \pm 19.6$ & $8.1 \pm 9.6$ & 0.000 \\
Thoracic kyphosis $\left({ }^{\circ}\right)$ & $35.5 \pm 21.7$ & $34.9 \pm 7.7$ & 0.951 \\
Segmental kyphosis $\left({ }^{\circ}\right)$ & $23.3 \pm 27.2$ & $10.1 \pm 3.1$ & 0.007 \\
T1-S1 height $(\mathrm{mm})$ & $322.9 \pm 63.4$ & $356.9 \pm 60.3$ & 0.088 \\
\hline
\end{tabular}


Table 3 Summary of radiographic parameters postoperatively and at the last follow-up

\begin{tabular}{llll}
\hline & Postoperation & Last follow-up & $P$ value \\
\hline Coronal curve $\operatorname{cobb}\left({ }^{\circ}\right)$ & $8.1 \pm 9.6$ & $11.7 \pm 12.2$ & 0.031 \\
Thoracic kyphosis $\left({ }^{\circ}\right)$ & $36.7 \pm 8.3$ & $37.6 \pm 7.5$ & 0.523 \\
Segmental kyphosis $\left({ }^{\circ}\right)$ & $10.1 \pm 3.1$ & $7.4 \pm 7.2$ & 0.346 \\
T1-S1 height $(\mathrm{mm})$ & $326.6 \pm 64.5$ & $388.7 \pm 78.9$ & 0.001 \\
Concave height $(\mathrm{mm})$ & $60.1 \pm 19.7$ & $73.1 \pm 23.7$ & 0.003 \\
Fusion segment height $(\mathrm{mm})$ & $56.9 \pm 22.9$ & $71.2 \pm 22.0$ & 0.002 \\
\hline
\end{tabular}

incarcerated hemivertebra will progress and create a wedge-shaped deformity during the spinal growth period [10]. In this situation, the conditions of most patients cannot be controlled with nonsurgical treatments like wearing orthosis. Thereby, most spine surgeon had reached a consensus on surgical treatment for congenital scoliosis due to hemivertebra.

At present, the recommended surgical options mainly include in situ fusion, convex growth arrest, and hemivertebra excision via a combined anterior and posterior approach in one or two stages [2, 11-13]. Currently, the one-stage posterior hemivertebra resection combined with bilateral transpedicular screw instrumentation has become the commonly adopted procedure for the correction of congenital scoliosis. The use of pedicle screws is a powerful method which allows excellent deformity correction in the coronal and sagittal planes, and is safe, even in very young children [10]. The pedicle screw instrumentation can effectively transmit the correction torque to the anterior and middle columns of the spine, increasing the compressive resistance of the anterior and middle columns [14]. Thereby, it helps retard the growth of vertebrae and prevents the crankshaft phenomenon.

Despite the major improvements in the treatment of congenital scoliosis due to hemivertebra, described, simple, and less-invasive methods were more acceptable and popular. The posterior unilateral transpedicular screw fixation could be an advisable alternative to further minimize the trauma in children and decrease the growth arrest of the concave side. Moreover, short-segment fusion can be performed to preserve more growing segments and motor units. Most of the concave pedicle was anomaly and tiny in malformed vertebra; thus, pedicle screw placement is very difficult, having to extend the instrument segment if bilateral transpedicular screw fixation was selected.

In the present study, the mean correction rates of the segmental curve and segmental kyphosis were $82.4 \%$ and $56.2 \%$, respectively. Deformities were satisfactorily corrected, and there were no significant losses during the follow-up, suggesting that unilateral transpedicular fixation can provide sufficient force for correction in children. These correction rates are in accordance with previous reports of posterior bilateral fixation describing similar case series $[13,15]$. For these patients with scoliosis progression in follow-up, including two curve progression in the proximal junction and two cases in the distal junction, insufficient fusion levels and complex congenital scoliosis may be the main cause.

Unilateral short-segment fixation requires pedicle screw strength. Pedicle fracture, which requires revision surgery, is the most common complication reported in previous studies $[16,17]$. In our series, only one patient experienced pedicle fracture that was revised. The patient with severe kyphoscoliosis due to T12 hemivertebrea shows proximal junction kyphosis in 7 months after initial hemivertebrectomy and unilateral fusion. The rigid curve, poor flexibility for kyphoscoliosis, and poor adherence for brace may be the cause. Many studies have confirmed that pedicle fractures are related to the surgical technique rather than to the weakness of the pedicle [15]. Therefore, we adopted the funnel technique in all cases to guarantee accuracy of the pedicle screw placement. Most important of all, the use of a brace post operation is very necessary, not only to protect the instrumentation, but also to maintain further correction. We recommend the minimum 6-month duration of brace use, even after the bone fusion is complete.

The safety of the pedicle screws in the pediatric spine and their effect on vertebral growth have been the topic of controversy in the literature, as some experimental studies have shown growth retardation secondary to pedicle screw instrumentation in immature animals [18, 19]. However, prior clinical studies have shown no growth-retardation effect of the pedicle screws in the pediatric spine [20]. A recent study by Xue et al. has also observed no negative effects of the pedicle screw instrumentation on vertebral bodies' growth. No spinal stenosis existed in an average of 7 years after instrumentation on CT axial images. In their study, 35 patients less than 7 years were consisted undergoing pedicle screw instrumentation [21].

The limitation of this study was that it is a retrospectively reviewed study with a small number of patients included; more patients are needed in the future. The other drawback was that all patients have been followed-up for at least 60 months, which are very young and far from mature bone; thus, continuous follow-up is needed in the future. In addition, this study does not contain results about life quality in the follow-up. Further trials about life quality, especially spinal mobilization and mental health status, are needed to be evaluated in the future.

\section{Conclusions}

Despite having some complications, posterior hemivertebrectomy and unilateral instrumented fusion are commendable procedures for early correction in young 
children. The safety and efficacy of the correction were proved by radiographic measurements. The growth of the non-fused concave side of the spine was observed. We concluded that it is a simple, secure, reliable, less-invasive, and well-tolerated technique that can successfully resolve this kind of congenital scoliosis in children.

\section{Abbreviations}

CGA: Convex growth arrest; LIV: Lowest instrumented vertebra; PJK: Proximal junction kyphosis; MRI: Magnetic resonance imaging; SPSS: Statistic Package for Social Science; CT: Computed tomography; UIV: Upper instrumented vertebra

\section{Acknowledgements}

Many thanks are given to our center colleagues and the devotion of the patients.

\section{Funding}

This work is supported by the National Natural Science Foundation of China (no. 81702212).

\section{Availability of data and materials}

The datasets used and/or analyzed during the current study are available from the corresponding author upon reasonable request.

\section{Authors' contributions}

XXH and ZS conceived and designed the study. XXH measured and recorded the data. XXH and ZS wrote the paper. ZS reviewed and edited the manuscript. Both authors read and approved the final manuscript.

\section{Ethics approval and consent to participate}

This retrospective study was approved and consented to participate by the Ethics Committee of The Second Hospital of Shanxi Medical University.

\section{Consent for publication}

All patients involved had given informed consent.

\section{Competing interests}

The authors declare that they have no competing interests.

\section{Publisher's Note}

Springer Nature remains neutral with regard to jurisdictional claims in published maps and institutional affiliations.

Received: 2 August 2018 Accepted: 10 September 2018 Published online: 20 September 2018

\section{References}

1. McMaster MJ, Ohtsuka K. The natural history of congenital scoliosis. A study of two hundred and fifty-one patients. J Bone Joint Surg Am. 1982:64:1128-47.

2. Winter RB, Moe JH, Eilers VE. Congenital scoliosis. A study of 234 patients treated and untreated. Part I: natural history. J Bone Joint Surg Am. 1968:50:1-15.

3. Kose KC, Inanmaz ME, Altinel L, Bal E, Caliskan I, Isik C, et al. Convex short segment instrumentation and hemi-chevron osteotomies for Putti type 1 thoracic hemivertebrae: a simple treatment option for patients under 5 years old. J Spinal Disord Tech. 2013;26(6):E240-7.

4. Ruf M, Harms J. Posterior hemivertebra resection with transpedicular instrumentation: early correction in children aged 1-6 years. Spine. 2003;28:2132-8.

5. Chu G, Huang J, Zeng K, Guo Q, Zhang H. A modified surgical procedure for congenital kyphoscoliosis: selective partial hemivertebrectomy via posterior-only approach. Childs Nerv Syst. 2015;31(6):923-9.

6. Andrew T, Piggot H. Growth arrest for progressive scoliosis: combined anterior and posterior fusion of the convexity. J Bone Joint Surg Br. 1985;67:193-7.
7. Uzumcugil A, Cil A, Yazici M, Acaroglu E, Alanay A, Aksoy C, et al. Convex growth arrest in the treatment of congenital spinal deformities: revisited. $J$ Pediatr Otrhop. 2004;24:658-66.

8. Demirkiran G, Yilmaz G, Kaymaz B, Akel I, Ayvaz M, Acaroglu E, et al. Safety and efficacy of instrumented convex growth arrest in treatment of congenital scoliosis. J Pediatr Orthop. 2014;34(3):275-81.

9. Viau M, Tarbox BB, Wonglertsiri S, Karaikovic EE, Yingsakmongkol W, Gaines RW. Thoracic pedicle screw instrumentation using the "Funnel Technique": part 2. Clinical experience. J Spinal Disord Tech. 2002;15(6):450-3.

10. Ruf $M$, Harms J. Hemivertebra resection by a posterior approach: innovative operative technique and first results. Spine. 2002;27:1116-23.

11. Callahan BC, Georgopoulos G, Eilert RE. Hemivertebral excision for congenital scoliosis. J Pediatr Orthop. 1997;17:96-9.

12. Holte DC, Winter RB, Lonstein JE, Denis F. Excision of hemivertebrae and wedge resection in the treatment of congenital scoliosis. J Bone Joint Surg Am. 1995;77:159-71.

13. Chang DG, Kim JH, Ha KY, Lee JS, Jang JS, Suk SI. Posterior hemivertebra resection and short segment fusion with pedicle screw fixation for congenital scoliosis in children younger than 10 years: greater than 7-year follow-up. Spine. 2015;40(8):E484-91.

14. Burton DC, Asher MA, Lai SM. Scoliosis correction maintenance in skeletally immature patients with idiopathic scoliosis. Is anterior fusion really necessary? Spine. 2000;25(1):61-8.

15. Zhang J, Shengru W, Qiu G, Yu B, Yipeng W, Luk KD. The efficacy and complications of posterior hemivertebra resection. Eur Spine J. 2011; 20:1692-702.

16. Hicks JM, Singla A, Shen FH, Arlet V. Complications of pedicle screw fixation in scoliosis surgery: a systematic review. Spine. 2010;35(11):E465-70.

17. Di Silvestre M, Parisini P, Lolli F, Bakaloudis G. Complications of thoracic pedicle screws in scoliosis treatment. Spine. 2007;32(15):1655-61.

18. Cil A, Yazici M, Daglioglu K, Aydingoz U, Alanay A, Acaroglu RE, et al. The effect of pedicle screw placement with or without application of compression across the neurocentral cartilage on the morphology of the spinal canal and pedicle in immature pigs. Spine. 2005;30(11):1287-93.

19. Fekete TF, Kleinstück FS, Mannion AF, Kendik ZS, Jeszenszky DJ. Prospective study of the effect of pedicle screw placement on development of the immature vertebra in an in vivo porcine model. Eur Spine J. 2011;20(11):1892-8.

20. Olgun ZD, Demirkiran G, Ayvaz M, Karadeniz E, Yazici M. The effect of pedicle screw insertion at a young age on pedicle and canal development. Spine. 2012;37:1778-84.

21. Xue X, Shen J, Zhang J, Li S, Wang Y, Qiu G. X-ray assessment of the effect of pedicle screw on vertebra and spinal canal growth in children before the age of 7 years. Eur Spine J. 2014;23(3):520-9.

Ready to submit your research? Choose BMC and benefit from:

- fast, convenient online submission

- thorough peer review by experienced researchers in your field

- rapid publication on acceptance

- support for research data, including large and complex data types

- gold Open Access which fosters wider collaboration and increased citations

- maximum visibility for your research: over $100 \mathrm{M}$ website views per year

At BMC, research is always in progress.

Learn more biomedcentral.com/submission 